\title{
Investigation of Radiated Emissions from GPS Based Vehicle Tracking System Board and it's comparison with different EMI /EMC Standards and Remedies to reduce the Radiations
}

\author{
Shreenivas R Jog, M. S. Sutaone, and V. V.Badawe
}

\begin{abstract}
In this research proposal, the Radiated Emissions from GPS based Vehicle Tracking System board (GPRS Based) have been investigated by using Agilent make Spectrum Analyser E4411-B, close-field EMI Probes 11940A and 11941A. Observations for Radiated Emissions are presented here as E-Field Strength, H-Field Strength and S-Power Density. Several techniques / methods to reduce radiation problems are studied and discussed. The ruggedised EMI enclosures using Aluminum, Silver filled conductive gaskets and Copper foil with conductive adhesives have been designed for GPS VTS (GPRS based) board. By implementation of EMI enclosure, the radiated emission reduced by around 20dB. The GPS VTS board with enclosure has been tested in the national EMI laboratory. These levels have been compared with EMI/EMC (Electromagnetic Interference/Electromagnetic Compatibility) standards like MIL-STD-461E and CISPR. The measured radiation level in frequency band $30 \mathrm{MHz}$ to $2.5 \mathrm{GHZ}$ has been restricted to around $25 \mathrm{~dB} \mu \mathrm{V} / \mathrm{m}$ in horizontal and vertical directions. The Radiated Emission level in frequency band 150 $\mathrm{KHz}$ to $30 \mathrm{MHz}$ has been found to be just at the border of MIL-461E. This level can be reduced by using Magnetic material like MuFerro 6800 sheet in enclosure. The designed enclosure meets compatibility requirements for Radiated Emission as per MIL-STD-461E, CISPR standard and radiation reduced to safer level for human being.
\end{abstract}

Index Terms-EMI/EMC, SIM508, GPS, EMI probe, VTS,GPRS

\section{INTRODUCTION}

Radiation from mobile phones and other electronic equipments may cause brain tumors, cancer, anxiety and memory loss. A wide variety of electrical devices contribute to electromagnetic radiation ranging from computers, to phones, TV sets, radar transmitter, mobile towers, transformers, etc. However, mobile phone radiation is certainly intense, as evidenced by the effects on aircraft navigation systems. [1] Also radiation can affect the operation of Electronic and Communication Systems badly. In view of this, it is required to design enclosures for electronic circuits, which emit less radiation to avoid harmful effects on human being and other electronic equipments.

Manuscript received February 10, 2012; revised March 14, 2012

Shreenivas R Jog is with Institute of Engineering and Technology Pimpri, Pune, India as Professor and HOD E and TC Department. (e-mail: srjog_etc@ redifmail.com)

M.S. Sutaone is with College of Engineering Pune, Pune, India as Professor and Head of Electronics and Telecommunication Department (e-mail: mssutaone@gmail.com).

V.V. Badawe is with Badawe Engineers Pvt. Ltd. (BEPL), Pune, India (e-mail: badawe@vsnl.net).

\section{ORIGIN OF THE RESEARCH PROBLEM}

Electromagnetic changes in the environment can adversely affect the energy balance of the human organism and it also contribute to disease. We are surrounded by stress-producing electromagnetic fields generated by the electrical wiring in the home and offices. Televisions, computers and video terminals, microwave ovens, overhead lights, power lines and the hundreds of motors can generate higher than normal gauss field strengths. The results in a particular study suggest that, $916 \mathrm{MHz}$ electromagnetic waves can promote malignant transformation of NIH/3T3 cells (established from the primary mouse embryonic fibroblast cells), induce cellular canceration. [2]

EMFs interact with living systems, affecting enzymes related to growth regulation, pineal gland metabolism (regulation of the sleep hormone, melatonin), cell division and multiplication. The persons who had been exposed to high-voltage lines in their early childhood had a two to three times higher risk of developing cancer, especially leukemia as compared to normal unexposed persons. EMFs from the high-voltage power lines also affect the neuro hormones of the brain. Since then, various studies have linked electromagnetic fields to increased incidence of heart disease, Alzheimer's disease, high blood pressure, headaches, sexual dysfunction, and blood disorders including a $50 \%$ increase in white blood count. [3]

The Exposure limits of radiation for mankind in terms of Power density is $10 \mathrm{~mW} / \mathrm{cm}^{2}\left(10 \mathrm{~dB} \mathrm{~mW} / \mathrm{cm}^{2}\right)$ for a period of 0.1 hour or more and in terms of Energy Density is 1 $\mathrm{mWh} / \mathrm{cm}^{2}$ during any 0.1 hour. [4]

If human beings are exposed to the radiated emission above these safer limits, they are likely to be affected by following health problems [4]:

- Eye Cataracts and Glaucoma,

- Thyroid Gland Sensitivity:

- Bradycardia: An interference with natural rhythm of heart, Chest pains, Organic injuries of cardiovascular system

- Humeral Radiation: Increase of Histamine content of blood.

- Decrease in sensitivity of eye and nose

- Vide variety of various nervous reactions like headache, fatigue.

- Breast Cancer.

- Brain Tumor. 


\section{METHODS TO MiNIMIZE RADIATED EMISSION}

The following methods / techniques are discussed to minimize Radiated Emission from Electronics equipments/ circuits.

\section{A. Component Selection and Circuit Design Aspects}

- Use slow and high noise immunity logic components.

- Operating the component in linear mode.

- Use RF suppressors like isolation transformer, optical isolators, and ferrite beads.

- Use RF chokes and inductors to confine RF energy to desired circuit.

- Use toroids to minimize leakage field of inductor

- Minimize signal bandwidth and maximize signal levels.

- Use watchdog Timer circuit for microprocessor / microcontrollers. [5]

- Oscillator circuits should be covered by conductive metallic bread on PCB.

- Use short lead lengths for RF components.

- Use feed through capacitors for inter stage coupling and power input connections to $\mathrm{RF}$ circuitry. [6]

- Use Electrostatic screening for transformers. [6]

\section{B. Use of Spike/Surge Protectors}

Use of transient absorbers/ MOV/ gas filled surge arrestors across Mains/DC/Signal lines is recommended to take care of electrostatic discharge and spikes on supply lines. This will protect the processor circuit from transients/ surges.

\section{Use of Filtering Techniques}

Use of Filtering techniques in power supply lines and signal input/output is recommended. Also filtering should be used in the circuits having interference sources. [5] Use of suitable RFI filters with X and Y Capacitors and proper grounding schemes can result into reduction of conducted emission level.

\section{Shielding Techniques}

EMI shielding can be done effectively by using specially designed metallic Enclosures made up of Copper, Aluminum, Aluminum alloy and Magnetic materials . The Enclosures can be sealed properly by using Copper Foil and suitable Conductive rubbers /gaskets. [5], [6]

\section{E. Selection of Shielded Cables}

Twisted / shielded Teflon cable should be used for minimizing electro-magnetic interference. Terminate shield to proper type of connectors. Shield is to be grounded at one end to avoid circulating current loops. Run cables away from apertures of shielding close to conductive grounding structures. Avoid resonant length of cables and consider damping cables with ferrite suppressors. Bunching of cables carrying identical electrical signals should be avoided to minimize cross-talk. Avoid pigtails while grounding the shield. Use Copper breaded conduits for cables to increase the shielding effectiveness especially in stringent conditions of radiation fields. The standard practices for routing of cables should be followed. [7]

\section{F. Multilayer PCB Design}

From EMI point of view, multi-layered PCB is recommended. [5] Multilayer boards are formed by etching few double sided boards and gluing them together. PCB design should follow standard practices like $20-\mathrm{H}$ rule for minimizing the EMI problems. [8] The recommended materials for PCB are fiber glass resin (FR-4), woven glass/ ceramic loaded, PTFE/Ceramic (Teflon) and GTEK. [8]

\section{G. Grounding Considerations}

The common ground impedance can be reduced by better grounding techniques. Single point grounding arrangement is recommended for low frequencies and multi-point grounding for high frequencies. The ground of Analog, Digital and RF circuits to be terminated to power supply ground separately. Floating ground arrangement is recommended to isolate circuits producing interference. Opto-isolator and isolation transformer can be used for this purpose. [5], [7]

The methods discussed above can be useful in reducing Radiated Emission from Electronics equipments/systems. [9]

\section{Methodologies IMPLEMENTED TO MinimizE RADIATED EMISSION FROM GPS VTS BOARD}

GPS VTS board (GPRS Based) is taken as a Model 1 for the research work. GPS VTS Board uses SIMCOM, SIM 508 based GPS/GPRS module for localization and positioning of vehicles on Local/ goggle Maps. [10] The GPS Vehicle Tracking (VTS) board consists of GPS, GPRS Modem, Switching Mode Power supply (SMPS), and Microcontroller which contribute in producing the radiations.

The rugedised enclosure designed for this board has been sealed with the help of silver filled conductive gaskets [11] and Copper foil with adhesives. The material used for enclosure is Aluminum (Alloy 6082) HE-30 (conductivity of $26.315 \times 10^{6}$ Siemens/m, lesser than pure Aluminum and Copper). [12] This material is selected because, it gives better mechanical strength and corrosion resistance to enclosure. The designed enclosure is having $3 \mathrm{~mm}$ thickness and it is chrome plated (120micron) for resistance to corrosion. The ruggedised enclosure and system is intended to work in mobile ground vehicle in stringent environmental, dynamic, and strategic conditions. The different EMI/EMC, environmental and dynamic test shall be conducted on the system.

HE-30 Enclosures were also designed for Model 2 with GPS VTS Transmitter / Receiver Boards and Radiated Emission test results conducted at national EMI test laboratory had been published in papers at reference $[9,13]$

Similarly Aluminum (Alloy 6063) HE-09 Enclosure was designed for GPS VTS Model 1 and 2. The results for Radiated Emission measured with EMI Probes on Spectrum Analyser had been published in the paper at reference [14].

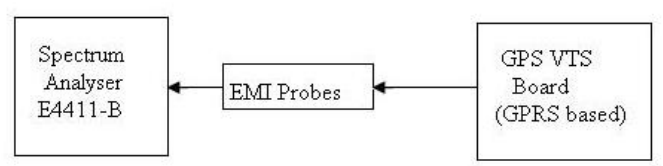

Fig. 1. Test set up for radiated emission measurement 


\section{Test SET Up FOR MEASUREMENT OF RADIATED EMISSION}

The EMI Probes 11940A and 11941A are handheld electromagnetic close field probes used with Agilent make Spectrum Analyzer E4411-B for observing the Radiated Emission obtained from device under test. [9, 15] The EMI probe has magnetic field sensor which gives output voltage proportional to the magnetic field. The probe gives spectrum of Radiated Emission giving amplitude and frequency with the help of Spectrum Analyzer. The initial readings are taken in $\mu \mathrm{V}$ and $\mathrm{dBm}$.

$$
\begin{gathered}
P_{m} d B m=10 \log _{10}\left(P_{m} / 1 m W a t t\right) \\
P_{m}=\left(V_{m}\right)^{2} / R, \text { Where, } R=50 \Omega \\
V_{S A} d B \mu V=20 \log _{10}\left(V_{m} \mu V / 1 \mu V\right)
\end{gathered}
$$

Equation (4) gives Magnetic field strength in $(\mathrm{dB} \mu \mathrm{A} / \mathrm{m})$

$$
\mathrm{H}=\mathrm{V}_{\mathrm{SA}}+\mathrm{AF}+\mathrm{K}
$$

where, $\mathrm{AF}=$ Antenna Factor in $\mathrm{dB}(\mu \mathrm{A} / \mathrm{m}) /(\mu \mathrm{V})$ for EMI Probes 11940A and 11941A. The value AF is obtained from the characteristics Antenna factors graph, plotted between frequency and Antenna factor. The Electric field strength in $(\mathrm{dB} \mu \mathrm{V} / \mathrm{m})$ is calculated using following equation, considering field impedance as $377 \Omega$.

$$
\begin{gathered}
\mathrm{E}=\mathrm{V}_{\mathrm{SA}}+\mathrm{AF}+\mathrm{K}+20 \log _{10}(377) \\
\mathrm{E}=\mathrm{V}_{\mathrm{SA}}+\mathrm{AF}+\mathrm{K}+51.1
\end{gathered}
$$

Similarly the Power Density in $\left(\mathrm{dB} \mathrm{mW} / \mathrm{cm}^{2}\right)$ calculated using following equation,

$$
\text { Power Density }=V_{S A}+A F+K-104.3
$$

$\mathrm{K}=$ loss or gain in dB between EMI Probes 11940A/ $11941 \mathrm{~A}$ and Spectrum analyzer (Positive value if loss, negative value if gain). Generally $\mathrm{K}$ is taken as zero. [9], [15]

\section{RADIATED EMISSION LIMITS AS PER CISPR AND MIL-STD-461E EMI/EMC STANDARD}

Table I, II and Fig. 2 give Radiated Emission limits as per EMI/EMC Standards CISPR and MIL-461E.

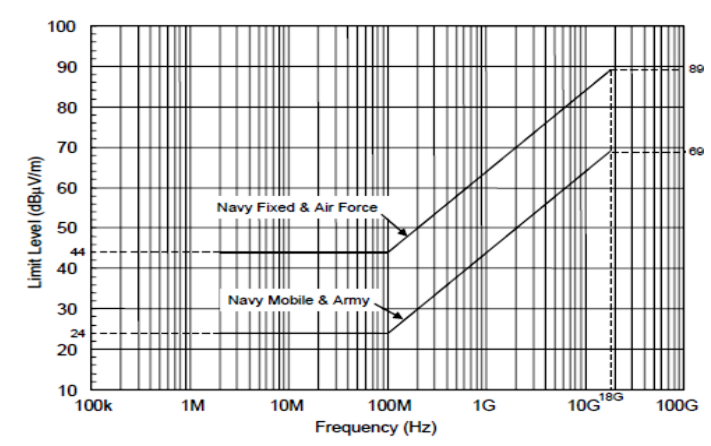

Fig. 2. RE 102 (MIL-STD-461E) for ground applications

TABLE I: CLASS A (COMMERCIAL EQUIPMENT) CISPR RE LIMITS.
\begin{tabular}{|l|l|l|}
\hline $\begin{array}{l}\text { Frequency } \\
(\mathrm{MHz})\end{array}$ & $\begin{array}{l}\text { Measuring } \\
\text { Distance }(\mathrm{m})\end{array}$ & $\begin{array}{l}\text { Field } \\
\text { Strength }(\mu \mathrm{V} / \mathrm{m})\end{array}$ \\
\hline $30-88$ & 30 & 30 \\
\hline $88-216$ & 30 & 50 \\
\hline $216-1000$ & 30 & 70 \\
\hline
\end{tabular}

TABLE II: CLASS B (RESIDETIAL EQUIPMENT) CISPR RE LIMITS.
\begin{tabular}{|l|l|l|}
\hline $\begin{array}{l}\text { Frequency } \\
(\mathrm{MHz})\end{array}$ & $\begin{array}{l}\text { Measuring } \\
\text { Distance }(\mathrm{m})\end{array}$ & $\begin{array}{l}\text { Field } \\
\text { Strength }(\mu \mathrm{V} / \mathrm{m})\end{array}$ \\
\hline $30-88$ & 3 & 100 \\
\hline $88-216$ & 3 & 150 \\
\hline $216-1000$ & 3 & 200 \\
\hline
\end{tabular}

\section{OBSERVATIONS AND RESULTS FOR RADIATED EMISSION}

Fig. 3 and Fig. 4 indicate the observed spectrums for radiated emission from GPS VTS Board (GPRS Based) with and without HE-30 Enclosure. The radiation levels are measured using Agilent make Spectrum Analyzer E4411-B and close field EMI Probes 11940A / 11941A and corresponding E- Field Strength $(\mathrm{dB} \mu \mathrm{V} / \mathrm{m}), \mathrm{H}$-Field Strength $(\mathrm{dB} \mu \mathrm{A} / \mathrm{m})$ and S-Power Density $\left(\mathrm{dBmW} / \mathrm{cm}^{2}\right)$ are calculated and shown in Table III.

Fig. 5 to Fig. 9 shows the observations for Radiated Emission Test on GPS VTS board (GPRS Based) with HE-30 enclosure, conducted at national EMI test laboratory, Automotive Research Association of India (ARAI), Pune, India. Test has been conducted as per MIL-STD-461E EMI standard. The distance betwwen GPS VTS Board and Antena in EMI chamber was kept as 1 Meter. The observations have been taken in both horizontal and vertical directions. These radiation levels have been compared with present standards like CISPR [7] and MIL-STD-461E. [16]

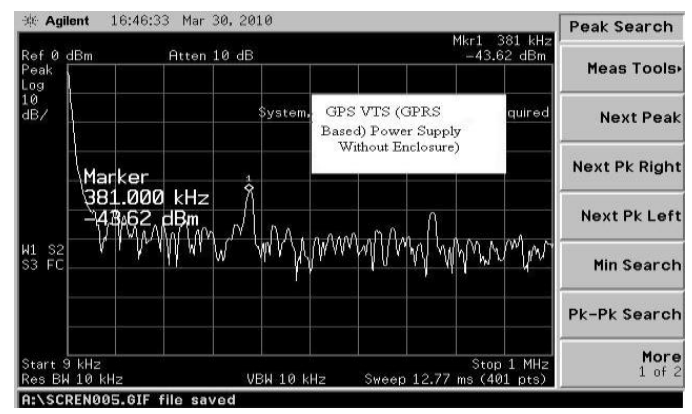

Fig. 3. Radiation from GPS VTS board (GPRS based) without enclosure

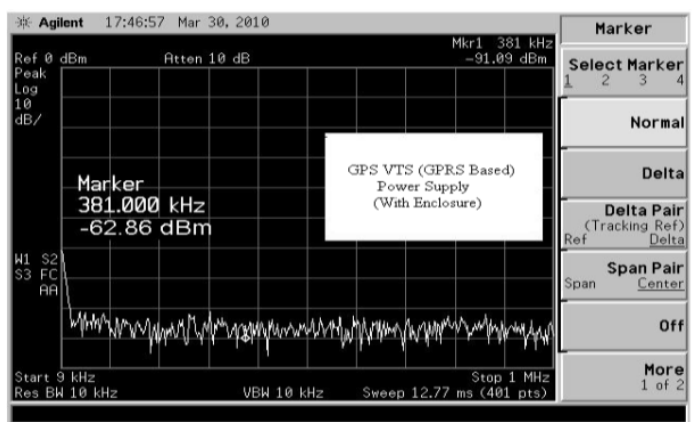

Fig. 4. Radiation from GPS VTS board (GPRS Based) with enclosure

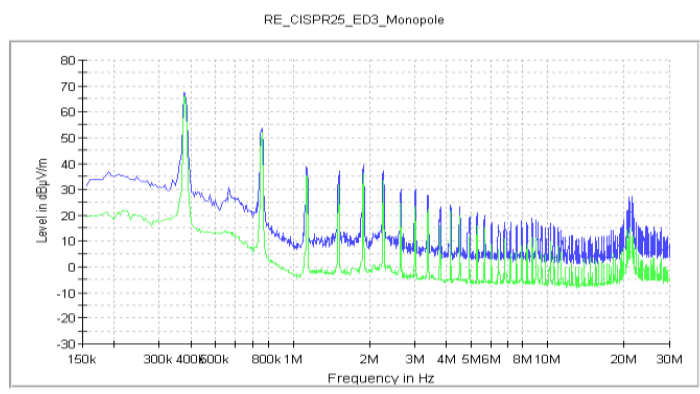

Fig. 5. RE Test (Horizontal direction) on GPS VTS board (GPRS based) with enclosure, Frequency Range: $150 \mathrm{KHz} \mathrm{Hz}$ to $30 \mathrm{MHz}$ 


\begin{tabular}{|c|c|c|c|c|c|c|c|c|}
\hline $\begin{array}{l}\text { Point of } \\
\text { observation on } \\
\text { GPS VTS Board }\end{array}$ & $\begin{array}{l}P_{m} \\
d B m\end{array}$ & $\begin{array}{l}\mathrm{V}_{\mathrm{m}} \\
\mathrm{uV}\end{array}$ & $\begin{array}{l}\mathrm{V}_{\mathrm{SA}} \\
\mathrm{dBuV}\end{array}$ & $\begin{array}{l}\mathrm{F} \\
\mathrm{KHz} / \mathrm{MHz}\end{array}$ & $\begin{array}{l}\mathrm{AF} \\
\mathrm{dB} \\
(\mu \mathrm{A} / \mathrm{m}) \\
/(\mu \mathrm{V})\end{array}$ & $\begin{array}{l}\mathrm{E} \\
\mathrm{dBuV} / \mathrm{m}\end{array}$ & $\begin{array}{l}\mathrm{H} \\
\mathrm{dB} \mu \mathrm{A} / \mathrm{m}\end{array}$ & $\begin{array}{l}\text { P.D } \\
\mathrm{dBmW} / \mathrm{cm}^{2}\end{array}$ \\
\hline $\begin{array}{l}\text { VTS (Without } \\
\text { HE-30 Enclosure) }\end{array}$ & -55.19 & 389.03 & 51.79 & $947 \mathrm{MHz}$ & 27 & 129.89 & 78.79 & -25.51 \\
\hline $\begin{array}{l}\text { VTS (With HE-30 } \\
\text { Enclosure) }\end{array}$ & -65.29 & 121.61 & 41.69 & $947 \mathrm{MHz}$ & 27 & 119.79 & 68.69 & -35.61 \\
\hline $\begin{array}{l}\text { VTS Power supply } \\
\text { (Without } \\
\text { HE-30Enclosure) }\end{array}$ & -43.62 & 1473.9 & 63.36 & $381 \mathrm{KHz}$ & 55 & 169.46 & 118.36 & 14.06 \\
\hline $\begin{array}{l}\text { VTS power supply } \\
\text { (With HE-30 } \\
\text { Enclosure) }\end{array}$ & -62.86 & 160.87 & 44.12 & $381 \mathrm{KHz}$ & 55 & 150.22 & 99.12 & -4.28 \\
\hline
\end{tabular}

Level in dB $\mu / \mathrm{m}$ RE_CISPR.25_ED3_Biocn_Log

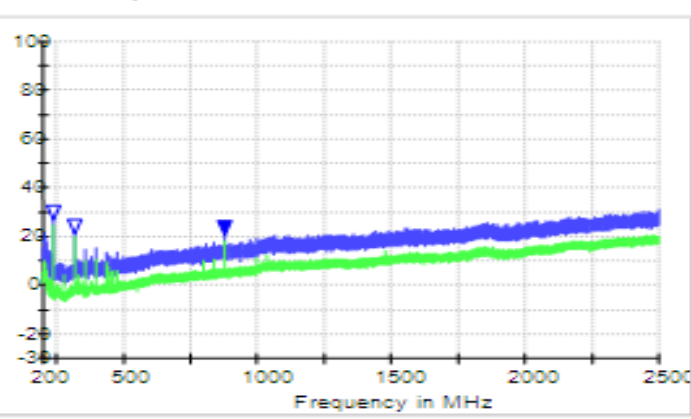

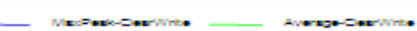

Fig. 6. RE Test (vertical direction) on GPS VTS board (GPRS based) with enclosure, frequency range: $200 \mathrm{MHz}$ to $2.5 \mathrm{GHz}$

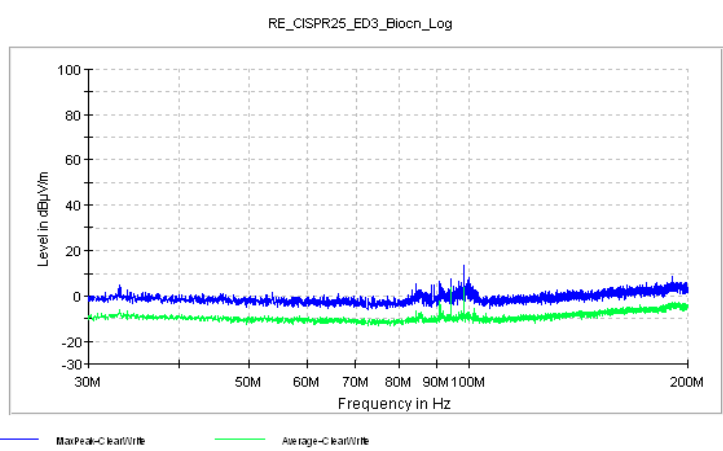

Fig. 8. RE Test (vertical direction) on GPS VTS board (GPRS based) with enclosure, frequency range: $30 \mathrm{MHz}$ to $200 \mathrm{MHz}$

Level in dBuV/m RE_CISPR.25_ED3_Biocn_Log

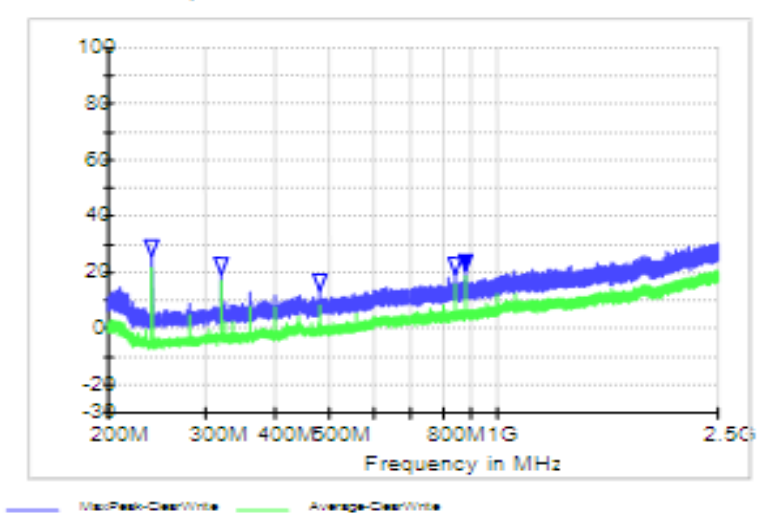

Fig. 7. RE Test (horizontal direction) on GPS VTS board (GPRS based) with enclosure, frequency range: $200 \mathrm{MHz}$ to $2.5 \mathrm{GHz}$

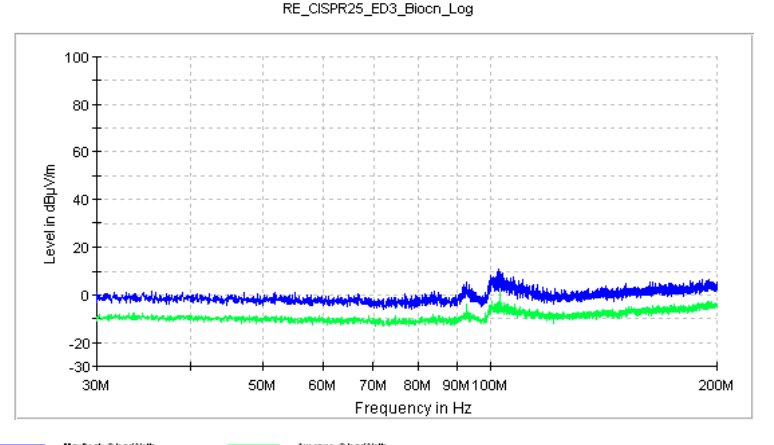

Fig. 9. RE Test (horizontal direction) on GPS VTS Board (GPRS based) with enclosure, frequency range: $30 \mathrm{MHz}$ to $200 \mathrm{MHz}$

From the Fig. 5 to Fig. 9, it can be verified that the Radiated Emission level for frequency band $30 \mathrm{MHz}$ to 2.5 GHZ in Horizontal and vertical directions found to be well within the limits as compared to MIL-461E. The Radiated Emission levels for frequency band $150 \mathrm{KHz}$ to $30 \mathrm{MHz}$ found to be just at boarder level of EMI/EMC Standard MIL-461E. This level could be reduced further by using sheet of low frequency magnetic shielding material like MuFerro 6800 in the enclosure. [17]

\section{CONCLUSION}

The remedial measures to minimize EMI / Radiated Emission problems have been discussed. The remedies suggested here are useful for reducing the radiation levels to safer limits. From the observations it is seen that GPS board (GPRS Based) gives the radiated emission which is greater than Power Density of $10 \mathrm{dBmW} / \mathrm{cm}^{2}$ (E-Field strength as $160 \mathrm{dBuV} / \mathrm{m})$. The radiation level from GPS VTS board found to be reduced by around $20 \mathrm{~dB}$ approximately when enclosed in HE-30 Aluminum enclosure. Also the Radiated Emission measured in test laboratory, for frequency band 30 $\mathrm{MHz}$ to $2.5 \mathrm{GHz}$ have been restricted to around $25 \mathrm{dBuV} / \mathrm{m}$ in both horizontal and vertical directions. The Radiated Emission levels for frequency band $150 \mathrm{KHz}$ to $30 \mathrm{MHz}$ has been found to be just at boarder level of EMI/EMC Standard MIL-461E. It could be restricted within the limits of MIL-461E by using Magnetic material like MuFerro 6800 sheet in enclosure. From the results, it is concluded that designed GPS VTS Model (GPRS Based) with enclosure is 
compatible with MIL-STD-461E, CISPR radiated emission standards and radiation levels are restricted to safer limits for human being.

\section{ACKNOWLEDGMENT}

The authors would like to sincerely thank Pd.Dr.D.Y.Patil Institute of Engineering Technology, Automotive Research Association of India (ARAI), University of Pune and Mr. Madhav Zambare for their valuable support and help for this research proposal.

\section{REFERENCES}

[1] G. Kuriger, H. Grant, A. Cartwrite, and D. Heirman, "Investigation of Spurious Emissions From Cellular Phones and the possible Effect on Aircraft Navigation Equipemnt," IEEE Transaction on Electromagnetic Compatibility,Vol.45 No 2, pp.281-292, May 2003,

[2] Y. Lei, W. M. Lian, H. D. Mei, and Z. Yi, "Cellular Canceration Induced by Mobile Phone Rediation," in Proc. Bioinformatics and Biomedical Engineering ,IEEE Conference (iCBBE), June 2010.

[3] H. Ross, K. Brenner, and B. Goldberg, "Electromagnetic Fields: The Dark side of the Technology," Available: http//innerself.com/Environmental/electromagnetic_fields.htm.

[4] P. L. Inglis, "The compatibility of man in microwave environment," IEEE Transaction on Electromagnetic Compatibility, vol. 11G, pp. 7-11, June 1969

[5] T. Williams, "EMC for product design," $4^{\text {th }}$ edition, Newness Publications, 2007.

[6] W. Boxleitner, "Electrostatic Discharge and Electronic Equipment," Practical guide for designing to prevent ESD Problems, Wiley-IEEE Press, October 1999.

[7] Henry W. Ott. "Noise Reduction techniques in electronics Systems", Wiley Interscience Publicatios, $2^{\mathrm{ND}}$ edition, 1987.

[8] E. Benedict, PCB Design for EMI/EMC Compliance, WEMPEC Seminar, $21^{\text {ST }}$ July 2000.

[9] S. Jog, M. S. Sutaone, and V. Badave, “HE-30 Aluminum Ruggediesd EMI Enclosure for GPS based Vehicle Tracking System," in Proc, IEEE, International conference on Wireless Communication, Vehicular Technology and Aerospace and Electronic System Technology (Wireless VITAE 2011), pp.1-5, Chennai, India, March 2011.

[10] User Guide and datasheet for SIMCOM, SIM508 GPS /GPRS module.

[11] Catlog for KuSaBa Engineers for EMI/EMC products, Available :http//www.kusabaengrs.com

[12] Datasheet for HE-30 Aluminum alloy 6082, Available: http\|www.aircraftmaterialsuk.com
[13] S. Jog, M. Sutaone, and V. Badave, "Evaluation of Electromegnetic Compatibility for GPS VTS Transmitter Board" in proc ,International Conference on Control,Communication and Power Engineering -2011 (CCPE-2011),Springer Publications, pp.436-439, November 2011,Pune,India.

[14] S. Jog, M. Sutaone, and V. Badave, "Performance comparision of EMI Enclosures for GPS Based Vehicle Tracking System" International Journal on Recent Trends in Engineering and Technology (IJRTET), Vol.6, issue2, pp 274-278 ,Nov-2011.

[15] Agilent Technology, Operation note on EMI probe 11940A and 11941A, November 2004.

[16] EMI/EMC Standard MIL-STD-461E, Revised: August 1999.

[17] Datasheet:MuFerrro6800,Available: http://www.hollandshielding.com

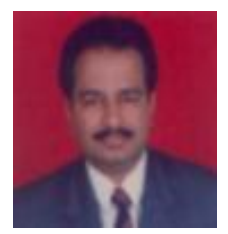

Shreenivas Jog is presently pursuing for $\mathrm{Ph} . \mathrm{D}$. in $\mathrm{E}$ and TC at College of Engineering Pune, affiliated to University of Pune, India. He has completed B.E and M.E (E and TC) from College of Engineering Pune. $\mathrm{He}$ has total experience of 22 years (15 years in academics and 7 years R and D at MELTRON, Pune, India).

His area of interest includes GPS, Mobile and Wireless Communication, EMI/EMC, Ruggedised and Defence Communications systems. He has published 31 papers in National and International Conferences /Journals. He is presently working as Professor and HOD (E and TC) in Pd. Dr. D.Y. Patil Institute of Engineering and Technology, Pimpri, Pune, India. He is Fellow of IETE and Member of IE and ISTE. He is Vice-Chairman of IETE Pune, India.

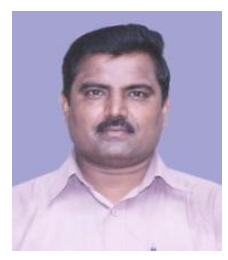

M. S. Sutaone is working as a Head of E and TC department, College of Engineering Pune and he has 25 years experience in academics and he has published more than 30 papers in National / International Conferences / Journals. His area of interest includes DSP, Image Processing, Mobile, VLSI and Wireless Communications systems.

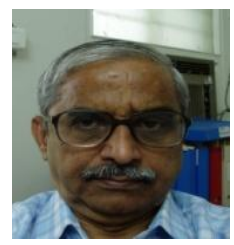

Vishweshwar Badave is working as Director BEPL Pune, India. He has more than 40 years of experience in R \& D. His area of interest includes Microwaves, Antennas, Radar, Defence wireless Communications systems, Ruggedisation of systems and EMI/EMC. 